\title{
Evaluation of growth, stemness, and angiogenic properties of dental pulp stem cells cultured in cGMP xeno-/serum-free medium
}

\author{
Chengjuan $\mathrm{Qu}^{1} \cdot$ Maria Brohlin $^{2,3} \cdot$ Paul J Kingham ${ }^{1} \cdot$ Peyman Kelk $^{1}$ (D)
}

Received: 22 January 2019 / Accepted: 12 December 2019 / Published online: 30 December 2019

(C) The Author(s) 2019

\begin{abstract}
This study was aimed to investigate the effects of cGMP xeno-/serum-free medium (XSF, Irvine Scientific) on the properties of human dental pulp stem cells (DPSCs). DPSCs, from passage 2, were cultured in XSF or fetal bovine serum (FBS)-supplemented medium, and sub-cultured up to passage 8. Cumulative population doublings (PDs) and the number of colony-forming-units (CFUs) were determined. qRT-PCR, ELISA, and in vitro assays were used to assess angiogenic capacity. Flow cytometry was used to measure CD73, CD90, and CD105 expression. Differentiation into osteo-, adipo-, and chondrogenic cell lineages was performed. DPSCs showed more elongated morphology, a reduced rate of proliferation at later passages, and lower CFU counts in XSF compared with FBS. Expression of angiogenic factors at the gene and protein levels varied in the two media and with passage number, but cells grown in XSF had more in vitro angiogenic activity. The majority of early and late passage DPSCs cultured in XSF expressed CD73 and CD90. In contrast, the percentage of CD105 positive DPSCs in XSF medium was significantly lower with increased passage whereas the majority of cells cultured in FBS were CD105 positive. Switching XSF-cultured DPSCs to medium supplemented with human serum restored the expression of CD105. The tri-lineage differentiation of DPSCs cultured under XSF and FBS conditions was similar. We showed that despite reduced CD105 expression levels, DPSCs expanded in XSF medium maintained a functional MSC phenotype. Furthermore, restoration of CD105 expression is likely to occur upon in vivo transplantation, when cells are exposed to human serum.
\end{abstract}

Keywords CD105 $\cdot$ cGMP xenogeneic serum-free culture $\cdot$ Human dental pulp stem cells $\cdot$ Mesenchymal stromal cell culture

\section{Introduction}

Mesenchymal stromal cells (MSCs) isolated from human dental pulp (DPSCs) have been shown to have multipotent differentiation capacity into various cell lineages, such as, neural ectodermal cells (Gronthos et al. 2002; Iohara et al. 2006), osteoblasts (Jo et al. 2007; Mori et al. 2011; Mortada and Mortada 2018; Otaki et al. 2007; Pettersson et al. 2017; Tabatabaei and Torshabi 2017), adipocytes (Gronthos et al. 2002; Iohara et al. 2006; Jo et al. 2007; Pettersson et al.
2017), odontoblasts (Gronthos et al. 2002), chondrocytes (Iohara et al. 2006), and myoblasts (Zhang et al. 2006). Moreover, DPSCs are considered to be a potent source of MSCs for orthopedic and oral-maxillofacial reconstructions in cell-based regenerative medicine due to their high efficiency of extraction, high capacity of proliferation and differentiation, plasticity, easy collection, and low morbidity, as well as their immunoregulatory properties. It has been reported that DPSCs have the ability to form densely calcified colonies and nodules (Gronthos et al. 2002; Gronthos et al. 2000; Huang
Peyman Kelk

peyman.kelk@umu.se

Chengjuan Qu

chengjuan.qu@gmail.com

Maria Brohlin

maria.brohlin@umu.se

Paul J Kingham

paul.kingham@umu.se
Department of Integrative Medical Biology, Umeå University, 901 87 Umeå, Sweden

2 Department of Clinical Microbiology, Infection and Immunology, Umeå University, 90187 Umeå, Sweden

3 Division of Clinical Immunology and Transfusion Medicine, Tissue Establishment, Cell Therapy Unit, Department of Laboratory Medicine, Umeå University Hospital, Daniel Naezéns väg, 907 37 Umeå, Sweden 
2009) and exhibit odontogenic features when transplanted into immunocompromised mice (Gronthos et al. 2002; Otaki et al. 2007). Furthermore, they can differentiate into osteoblasts, producing living autologous fibrous bone tissue which forms lamellar bone-containing osteocytes after transplantation into immnunocomprised mice (Laino et al. 2005).

In cell-based therapies, in vitro expansion of the DPSCs is necessary ahead of cell transplantation. Thus, identification of an optimal in vitro culture condition is needed. The standard in vitro culture medium for DPSCs, as well as other MSCs (Qu et al. 2014; Qu et al. 2016), has used supplementation of a base medium with fetal bovine serum (FBS) in order to provide essential factors to maintain cell survival and growth. Unfortunately, the FCS-derived xeno antigens and potentially infectious substances could cause immune reactions or contamination to the recipients of DPSCs. Furthermore, the variations between different lots of "ill-defined" FBS could lead to inconsistent performance. Therefore, various xeno-/serumfree medium formulations have been developed for in vitro culture of MSCs prior to cell transplantation (Bonnamain et al. 2013; Fujii et al. 2018; Hirata et al. 2010; Khanna-Jain et al. 2012; Mochizuki and Nakahara 2018; Xiao et al. 2018). It has been shown that DPSCs-cultured in xeno-/serum-free medium can maintain MSC morphological appearance, multipotent differentiation capacities, and expression of MSC-associated CD markers. However, there are conflicting conclusions regarding the effect on cell proliferation in comparison with FBS-supplemented media (Fujii et al. 2018; Hirata et al. 2010; Khanna-Jain et al. 2012; Xiao et al. 2018).

Angiogenesis is critical for tissue regeneration and repair. DPSCs have the potential to induce tissue vascularization either by secretion of angiogenic factors to promote vascularization via local endothelial cells or by differentiating toward vascular endothelium (Rehman et al. 2003; Ziegelhoeffer et al. 2004). It has been shown that the secreted paracrine factors in DPSCs-conditioned medium significantly accelerate adhesion, proliferation, and migration of human umbilical vein endothelial cells (HUVECs), as well as their tubulogenesis, and can alter the angiogenic gene and protein expression (Gharaei et al. 2018).

Previously, we showed that bone marrow-derived MSCs (BM-MSCs) and adipose tissue-derived MSCs (ASCs) cultured in a serum-free medium (MesenCult-XF) proliferated faster compared with FBS containing medium but had significantly reduced expression of the MSC marker, CD105 (Brohlin et al. 2017). However, to be able to use DPSCs clinically, the cells should be preferably cultivated in a defined medium produced under conditions of current good manufacturing practice (cGMP) (Bakopoulou et al. 2017). Previous studies have also shown that human serum was a suitable alternative to FBS for expansion of DPSCs while keeping their angiogenic potential and regenerative capacity (Khanna-Jian et al. 2012; Piva et al. 2017). Therefore, in the current study, we aimed to investigate the effect of a new cGMP xeno-/serum-free medium (XSF; PRIME-XV® MSC expansion XSFM, Irvine Scientific, USA) on DPSCs in vitro applications prior to future in vivo experiment. More specifically, we investigated whether this XSF medium could affect (1) DPSCs proliferation and phenotype, (2) the angiogenic effects of the DPSCs, and (3) the expression levels of MSCassociated CD markers and if so, whether any changes could be restored by exposure to human serum, which would occur upon in vivo cell transplantation.

\section{Materials and methods}

\section{Ethical permission, consent, and teeth harvest}

Collection, culture, storage, and usage of all clinical isolates in this study were approved by the local ethics committee for research at Umeå University (Dnr 2013-276-31M), and all methods were performed in accordance with the relevant guidelines and regulations of the local ethics committee. Informed consent was obtained from all donors and/or their legal guardians. Six donors with impacted healthy premolars or third molars planned for surgical removal due to orthodontic treatment or as pre-treatment before orthognathic surgery were selected for this study. The selected teeth with at least $30 \%$ root formations were surgically removed from six donors (age range 14-25 years) at the Maxillofacial Surgery Section at the University Hospital, Umeå. In initial studies, we used DPSCs from three human donors, as previously described and characterized in our recent study (Pettersson et al. 2017). Further experiments used an additional three donors.

\section{Cell isolation and culture}

Briefly, healthy dental pulp tissue was collected from the donors, minced and enzymatically digested in a solution containing $3 \mathrm{mg} / \mathrm{ml}$ collagenase type I (Worthington Biochemicals Corp) and $4 \mathrm{mg} / \mathrm{ml}$ dispase II (Roche Diagnostic/Boehringer Mannheim Crop) for $1 \mathrm{~h}$ in $37{ }^{\circ} \mathrm{C}$ with $5 \% \mathrm{CO}_{2}$. Subsequently the digested tissues were filtered through a $70-\mu \mathrm{m}$ strainer (Falcon, BD Labware) to obtain single-cell suspensions. The cells were then seeded at a cell density of $1 \times 10^{4}$ cells $/ 25 \mathrm{~cm}^{2}$ flask and cultured at $37^{\circ} \mathrm{C}$ with $5 \% \mathrm{CO}_{2}$, in MSC medium which consisted of Minimum Essential Medium- $\alpha$ ( $\alpha$-MEM with Glutamax; Invitrogen, Carlsbad, USA) supplemented with 15\% FBS (Sigma-Aldrich, St. Louis, MO, USA) and 1\% penicillin/ streptomycin (Gibco, USA). Upon reaching approximately $90 \%$ confluence, the cells were detached with trypsin/EDTA (Gibco, UK) and passaged to new $75-\mathrm{cm}^{2}$ flasks at a cell density of $5000 \mathrm{cells} / \mathrm{cm}^{2}$. The passage 1 cells were routinely characterized for MSC-associated CD markers (positive markers: CD73, CD90, CD105 and CD146; and negative markers: CD11b, 
CD19, CD34, CD45 and HLA-DR) using flow cytometry and differentiated toward osteoblasts and adipocytes, as previously described (Pettersson et al. 2017).

When DPSCs from passage 1 reached $80-90 \%$ confluence, the cells were enzymatically detached, counted and re-seeded in XSF or FBS medium, and continued in culture in the same medium to passage 6 for the below mentioned analyses. Moreover, the XSF-cultured DPSCs in passage 4 were also cultured in MEM- $\alpha$ containing 10\% human serum (H4522, Sigma-Aldrich) in parallel with continued cultures in XSF medium to passage 6. These DPSCs cultured in XSF or medium containing FBS or human serum were then analyzed for the MSC-associated CD markers by flow cytometry.

\section{Cell proliferation and colony-forming unit assay}

DPSCs were expanded under two different culture conditions: XSF (PRIME-XV® MSC expansion XSFM, Irvine Scientific, USA) or MEM- $\alpha$ medium containing FBS (10\%). Briefly, when DPSCs from passage 1 reached $80-90 \%$ confluence, the cells were enzymatically detached, counted, and re-seeded in XSF or FBS medium at a cell density of 30,000 cells $/ 25 \mathrm{~cm}^{2}$ flask and cultured for 1 week without medium change. Subsequently, the cells were counted with a hemocytometer and replated every week through to passage 6. Population doublings (PDs) were calculated using the following Eq. 1:

$\mathrm{PD}=[$ duration $\times \log (2)] /[\log ($ Final cell amount $)-\log ($ Initial cell amount $)]$

DPSCs from passage 2 and passage 6 were used in the CFU assay. Briefly, 300 DPSCs were seeded to a $25-\mathrm{cm}^{2}$ flask and cultured in XSF or FBS medium for 2 weeks without medium change. At the end of culture, the DPSCs were fixed and stained with $0.1 \%(\mathrm{w} / \mathrm{v})$ toluidine blue prepared in $2 \%(\mathrm{w} / \mathrm{v})$ paraformaldehyde for $1 \mathrm{~h}$, and subsequently rinsed with distilled water. Colonies ( $\geq 50$ cells) were then counted and scored as a CFU. The experiments were performed using samples three different donors $(N=3 ; n=3)$.

\section{Quantitative reverse transcription polymerase chain reaction}

Total RNA was extracted from DPSCs at passages 2 and 6, cultured under the two conditions XSF and FBS, using an RNeasy mini kit according to the manufacturer's instructions (Qiagen, Hilden, Germany). The RNA was quantified with a Nanodrop-2000c spectrophotometer (ThermoFisher Scientifc, Sweden), and complementary DNA (cDNA) was synthesized using iScript cDNA synthesis kit (Bio-Rad, CA, USA) with $0.4 \mu \mathrm{g}$ of RNA in $20 \mu \mathrm{l}$ reaction volume. Each $10 \mu \mathrm{l}$ RT-PCR reaction contained $4 \mu \mathrm{l}(4 \mu \mathrm{g})$ of $\mathrm{cDNA}, 6 \mu \mathrm{l}$ of SsoFast ${ }^{\mathrm{TM}}$ EvaGreen supermix master mixture (Bio-Rad), and forward and reverse primers for either angiopoietin-1 (ANGPT1; $200 \mathrm{nM}$ ), vascular endothelial growth factor A (VEGFA; $300 \mathrm{nM}$ ), or ribosomal protein L13a (RPL13a; $300 \mathrm{nM})$. The sequences of the primer pairs are shown in Table 1. The qRT-PCR analyses of these genes were performed in a CFX96 Real-Time PCR Detection System (BioRad Laboratories, Inc.). The amplification efficiencies were calculated from standard curves of the qRT-PCR reactions from each primer pair, and the relative gene expression levels of the genes, human ANGPT1 (Kim et al. 2010), and VEGFA (Otrock et al. 2007) were calculated with Pfaffl-method (Pfaffl 2001) by normalization to the housekeeping gene RPL13a (Studer et al. 2012). Efficiencies in the range of 90-110\% were accepted, and the specificities of the PCR products were determined with $3 \%(\mathrm{w} / \mathrm{v})$ agarose gel electrophoresis separation. The experiments were performed using samples from three different donors $(N=3 ; n=3)$.

ANGPT1: angiopoietin-1; VEGFA: vascular endothelial growth factor A; RPL13a: ribosomal protein L13a.

\section{Enzyme-linked immunosorbent assay}

Conditioned medium collected from DPSCs was used to analyze human angiopoietin-1 and VEGFA by using a sandwich ELISA kit (RayBiotech Inc., Norcross, USA) according to the manufacturer's protocol. The conditioned medium was collected from DPSCs at passage 2 and 6 just before the cells were expanded to next passage in XSF or FCS, respectively. The collected medium was frozen at $-80{ }^{\circ} \mathrm{C}$ prior to analysis. All samples were analyzed in duplicate $(100 \mu \mathrm{l} /$ well $)$, and the absorbance was measured at $450 \mathrm{~nm}$ on a Synergy microplate reader (BioTek, USA). The quantity of factors $(\mathrm{pg} / \mathrm{ml}$ ) were calculated against standard curves produced using recombinant proteins provided in the kits and normalized to the final number of cells at each passage. The experiments were performed using samples from three different donors $(N=3 ; n=3)$.

Angiogenesis assay As described above, the conditioned medium collected from DPSCs at passage 2 and 6 was stored at $-80{ }^{\circ} \mathrm{C}$ before use in angiogenesis assays. The evaluation of tube capillary formation in human umbilical vein endothelial cells (HUVECs, Gibco, USA) in the presence of conditioned medium (XSF and FBS) was examined using a commercially available angiogenesis assay kit (Millipore). Briefly, $1 \times 10^{4}$ HUVECs in $250 \mu$ l of cell suspension, which contained a mixture of $100 \mu$ l conditioned medium and $150 \mu$ l related control medium (XSF or FBS), were seeded onto the surface of polymerized ECMatrix ${ }^{\mathrm{TM}}$ in a 48 -well plate in triplicates. The HUVECs were allowed to adhere to the plate for 4-6 h before tube formation was examined by a light microscopy (Olympus IX71 microscope, Japan). Five random regions from each well were photographed using a ColorViewII digital camera (Soft Imaging System) and analyzed with 
Table 1 Human primers used for quantitative RT-PCR

\begin{tabular}{|c|c|c|c|c|c|}
\hline Primer & Forward $\left(5^{\prime} \rightarrow 3^{\prime}\right)$ & Reverse $\left(5^{\prime} \rightarrow 3^{\prime}\right)$ & $\begin{array}{l}\text { Annealing temperature } \\
\left({ }^{\circ} \mathrm{C}\right)\end{array}$ & Accession number & Reference \\
\hline ANGPT1 & $\begin{array}{l}\text { CAGAAAACAGTGG } \\
\text { GAGAAGATATAACC }\end{array}$ & $\begin{array}{l}\text { TGCCATCGTGTTCT } \\
\text { GGAAGA }\end{array}$ & 63 & NM001146.3 & Kim et al. (2010) \\
\hline VEGFA & $\begin{array}{l}\text { ATCTGCATGGTGAT } \\
\text { GTTGGA }\end{array}$ & $\begin{array}{l}\text { GGGCAGAATCAT } \\
\text { CACGAAG }\end{array}$ & 60.4 & NM001025366.3 & Zaher et al. (2007) \\
\hline RPL13a & $\begin{array}{l}\text { AAGTACCAGGCAGT } \\
\text { GACAG }\end{array}$ & $\begin{array}{l}\text { CCTGTTTCCGTAG } \\
\text { CCTCATG }\end{array}$ & 58 & NM012423.3 & Studer et al. (2012) \\
\hline
\end{tabular}

ImagePro Plus software (Media Cybernetics, MD, USA) for the number of closed networks and total capillary length. Each sample was examined with three parallel samples (15 images/ sample). The experiments were performed using samples from three different donors $(N=3 ; n=3)$. Due to the variations in the cell proliferation in the different culture conditions, the results for the number of the closed networks and total capillary lengths were normalized for equivalent cell numbers (using conditioned media secreted from 2000 cells).

\section{Flow cytometry}

DPSCs expanded under three different culture conditions; XSF or MEM- $\alpha$ medium containing FBS, or in MEM- $\alpha$ medium containing human serum, have been analyzed for flow cytometry. DPSCs, at different passages, were examined for the expression of positive MSCs-associated CD markers (CD73, CD90, and $\mathrm{CD} 105)$ and expected negative markers cocktail (CD11b, CD19, CD34, CD45, and HLA-DR) (Table 2). According to the manufacturer's protocol (BD, Bioscience, CA, USA), DPSCs were incubated with PE-conjugated antibodies [CD73 (1:25), CD90 (1:33) or CD105 (1:25)] and negative markers cocktail [CD11b, CD19, CD34, CD45, and HLA-DR (1:25)]. PE mouse IgG1 $\kappa$ isotype control (BD Pharmingen) was used as a corresponding control for all positive CD markers. PE hMSC isotype control, negative cocktail (BD Stemflow) was used as a corresponding isotype negative control. A total of 10,000 cells for each antibody were analyzed using a BD
Accuri $^{\mathrm{TM}}$ C6 Plus flow cytometer (BD Bioscience) as previously described (Kolar et al. 2017). The various experiments were repeated from either three or six different donors $(\mathrm{N}=3, \mathrm{n}=3$; $N=6, n=6$ ).

\section{Differentiation assays}

The DPSCs at passage 4 were cultured either in XSF or FBS medium to confluence, detached with trypsin/EDTA, and then re-seeded at a cell density of $5 \times 10^{4}$ cells per well in a 24-well plate and cultured in XSF or FBS culture medium until confluence. Subsequently, osteogenesis or adipogenesis was initiated by changing to respective differentiation media. The osteogenic medium contained DMEM, low glucose (+Glutamax, Gibco, UK) supplemented with 10\% FBS, $100 \mathrm{IU} / \mathrm{ml}$ penicillin, $100 \mu \mathrm{g} / \mathrm{ml}$ streptomycin, $100 \mathrm{nM}$ dexamethasone (Sigma-Aldrich), $10 \mathrm{mM} \beta$-glycerophosphate (Fluka, Steinheim, Germany), and $0.2 \mathrm{mM}$ 2-phosphate-Lascorbic acid trisodium salt (Wako, Japan). Adipogenic medium consisted of DMEM, low glucose (+Glutamax) supplemented with $10 \%$ FBS, $100 \mathrm{IU} / \mathrm{ml}$ penicillin, $100 \mu \mathrm{g} / \mathrm{ml}$ streptomycin, $1 \mu \mathrm{M}$ dexamethasone, $10 \mu \mathrm{g} / \mathrm{ml}$ insulin (SigmaAldrich), $0.5 \mathrm{mM}$ 3-isobutyl-1-methylxanthine (SigmaAldrich), and $100 \mu \mathrm{M}$ indomethacin (Sigma-Aldrich). The differentiation was performed in monolayer cultures for 4 weeks with medium changes every second day. Normal MSC culture growth medium with FBS was used as control. At the end of differentiation, the cells were fixed and the

Table 2 Detailed information of antibodies used for the flow cytometry analysis in the study

\begin{tabular}{|c|c|c|c|c|}
\hline Antibody & Brand & Clone number & Isotype & Host species \\
\hline CD73 & BD Pharmingen ${ }^{\mathrm{TM}}$ & AD2 & Mouse IgG1, $\mathrm{k}$ & Murine \\
\hline CD90 & BD Pharmingen ${ }^{\mathrm{TM}}$ & $5 \mathrm{E} 10$ & Mouse BALB/c IgG1, k & Murine \\
\hline CD105 & BD Pharmingen $^{\mathrm{TM}}$ & 266 & Mouse BALB/c IgG1, k & Murine \\
\hline PE mouse IgG1, $\kappa$ isotype control & BD Pharmingen ${ }^{\mathrm{TM}}$ & MOPC-21 & Mouse IgG1, $\kappa$ & Murine \\
\hline PE hMSC negative cocktail & BD Stemflow $^{\mathrm{TM}}$ & $\begin{array}{l}\text { CD34 (Clone 581) CD11b PE } \\
\text { (Clone: ICRE44) CD19 PE } \\
\text { (Clone: HIB19) CD45 PE } \\
\text { (Clone: HI30) HLA-DR PE(Clone G46-6) }\end{array}$ & Mouse IgG1, $\mathrm{k}$ & Murine \\
\hline $\begin{array}{l}\text { PE hMSC negative isotype } \\
\text { control cocktail }\end{array}$ & BD Stemflow ${ }^{\mathrm{TM}}$ & mIgG1, к PE $($ Clone $\times 40)$ & Mouse IgG1, $\mathrm{k}$ & Murine \\
\hline
\end{tabular}


osteogenic or adipogenic differentiated cells were incubated with $2 \%$ Alizarin Red S (pH 4.1) or $0.36 \%$ Oil Red O (w/v) at room temperature for 30 or $50 \mathrm{~min}$. Subsequently, the stained cells were photographed under light microscopy after thorough washes with water. The experiments were performed using samples from three different donors $(N=3, n=3)$.

Once the DPSCs at passage 4 reached confluence either in XSF or FBS culture conditions, chondrogenic differentiation of the DPSCs were performed with $5 \times 10^{5}$ cells in pellet culture in 15-ml tubes for 4 weeks. Chondrogenic medium contained serum-free $\alpha$-MEM supplemented with $40 \mu \mathrm{g} / \mathrm{ml} \mathrm{L}$-proline (Sigma-Aldrich), $100 \mu \mathrm{g} / \mathrm{ml}$ sodium pyruvate (Serva, Heideberg, Germany), $100 \mu \mathrm{M}$ dexamethasone, 1\% ITS +3
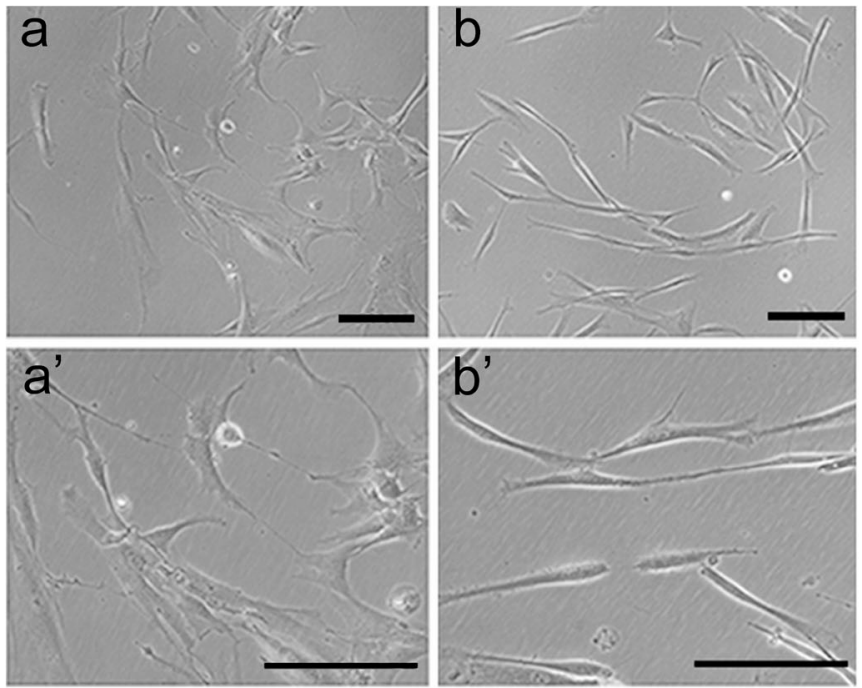

FBS

XSF

Passage 2

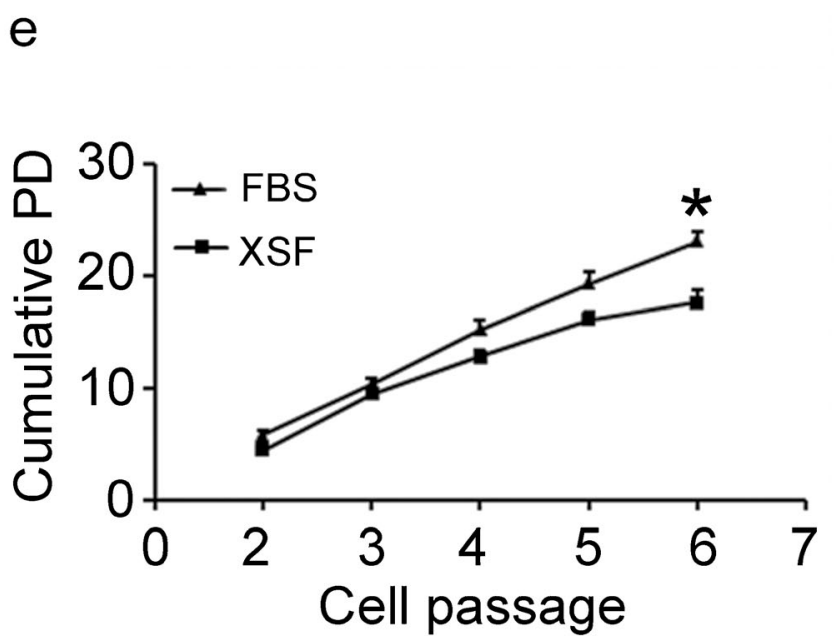

Fig. 1 Morphology and proliferation of DPSCs. Morphological appearance of DPSCs $\left(a-d^{\prime}\right)$ when cultured in FCS or XSF medium. Cumulative population doublings (PD) in (e) and number of colonyforming unit (CFU) in (f) of DPSCs-cultured in XSF or FBS medium. liquid media supplement (Gibco), $50 \mu \mathrm{g} / \mathrm{ml}$ ascorbate 2-phosphate, and $10 \mathrm{ng} / \mathrm{ml} \mathrm{TGF-} \beta_{3}$ (Peprotech, New Jersey, USA) (Kaitainen et al. 2013; Qu et al. 2014). The medium was changed every second day during the differentiation period. Pellets grown in normal MSC growth medium with FBS, which contained no chondrogenic factors, were used as control. At the end of chondrogenic differentiation, the pellets were fixed and prepared for frozen sections with $10 \mu \mathrm{m}$ thickness, then stained with $1 \%$ toluidine blue (Serva, Heidelberg, Germany) for proteoglycans (Kaitainen et al. 2013; Qu et al. 2012). The stained sections were photographed by a light microscopy. The experiments were performed from three different donors $(N=3, n=3)$.
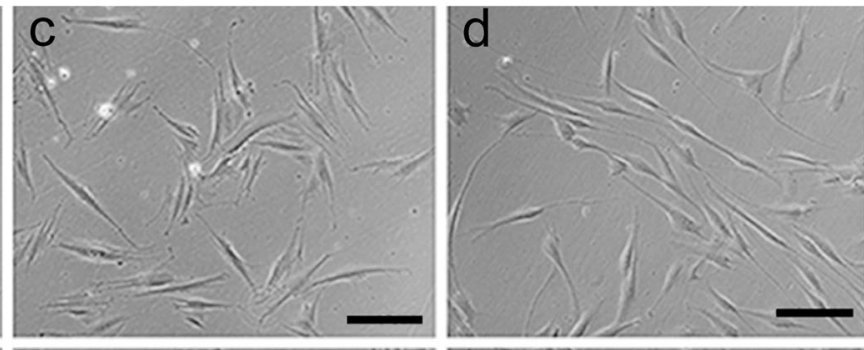

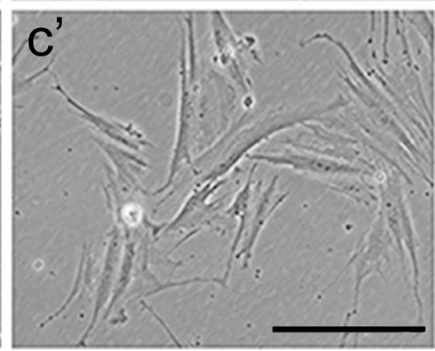

FBS

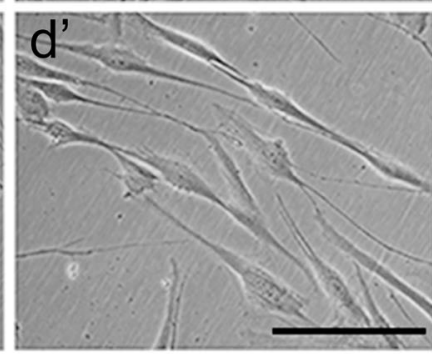

XSF f

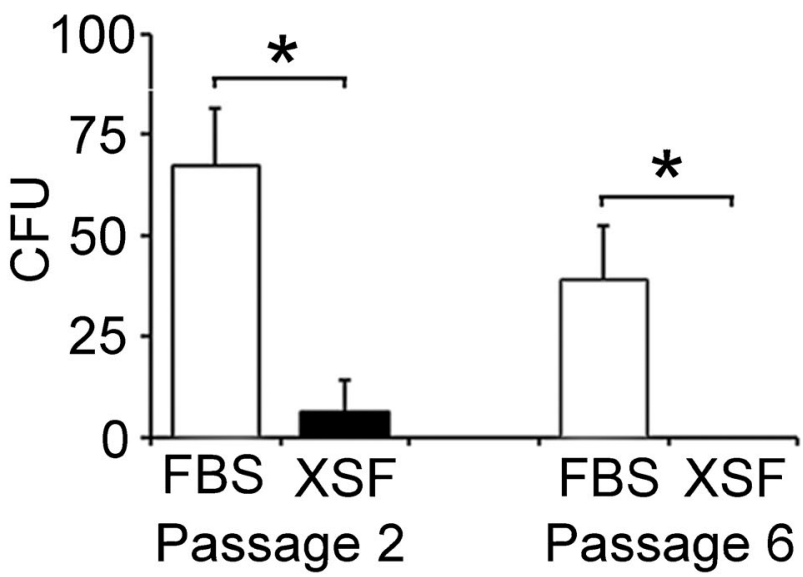

The experiments were repeated three times with DPSCs from three individual donors. The histograms show mean \pm SD from three individual donors $(N=3 ; n=3)$. * represents $p<0.05$. Scale bar $=100 \mu \mathrm{m}$ 
Fig. 2 Quantitative RT-PCR and ELISA analyses. The gene and secreted protein levels for ANGPT1/angiopoietin-1 (a, b) and VEGFA $(\mathbf{c}, \mathbf{d})$ in DPSCs from passage 2 and passage 6 in XSF or FBS culture conditions were analyzed with qRT-PCR and ELISA. The experiments were repeated three times with DPSCs from three individual donors. The histograms show mean \pm SD from three individual donors $(N=3$; $n=3)$. * represents $p<0.05$. VEGFA: vascular endothelial growth factor A; nd: not detectable

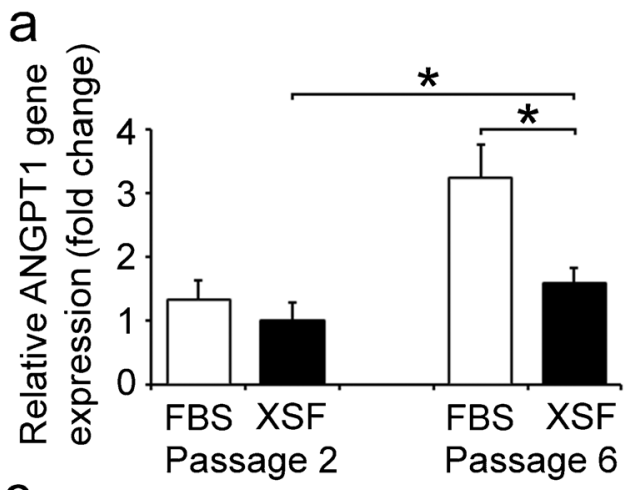

C

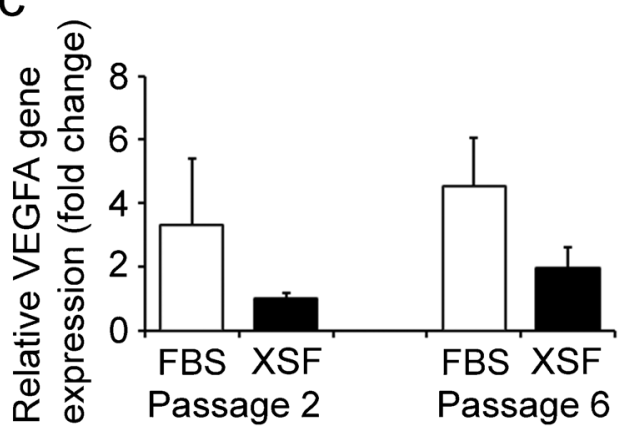

b
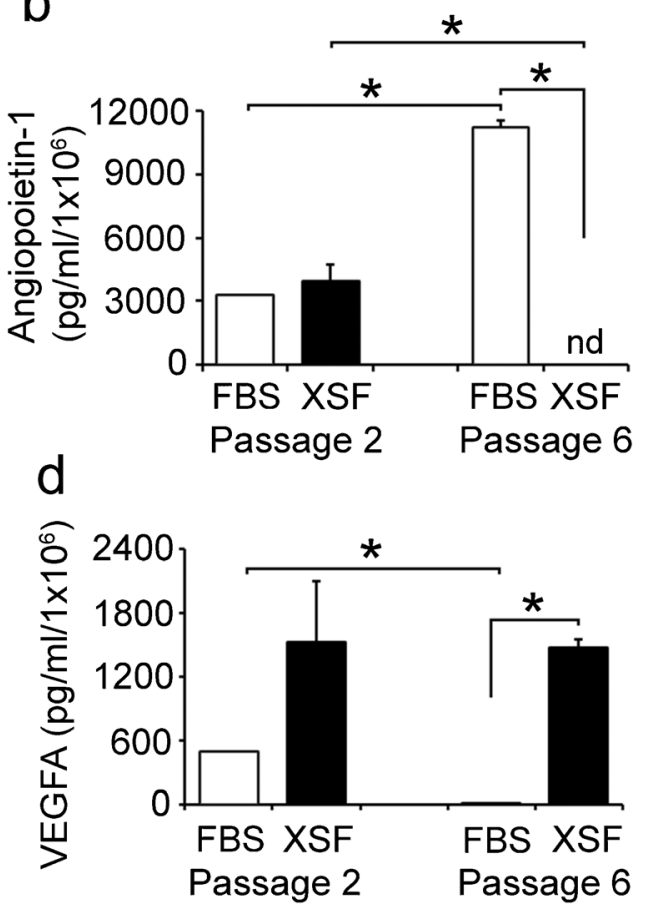

\section{Statistics}

Statistical analyses were performed using SPSS software, version 24 (IBM SPSS Statistics 24). Data were tested for normality using Shapiro-Wilk test, and thereafter, a sample paired $T$ test was used to test for statistically significant differences. For non-parametric data, Wilcoxon signed-rank test was used. $P$ values $<0.05$ were considered as statistical significance.

\section{Results}

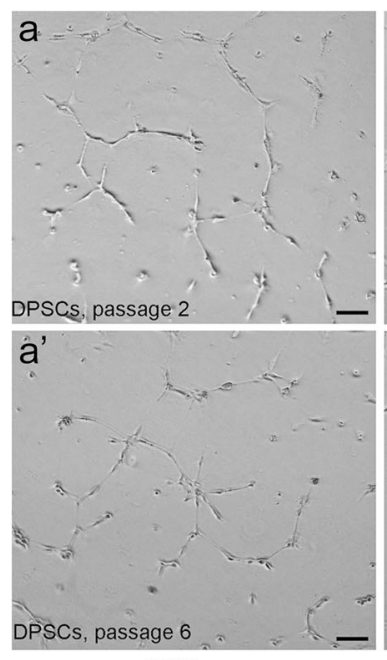

FBS
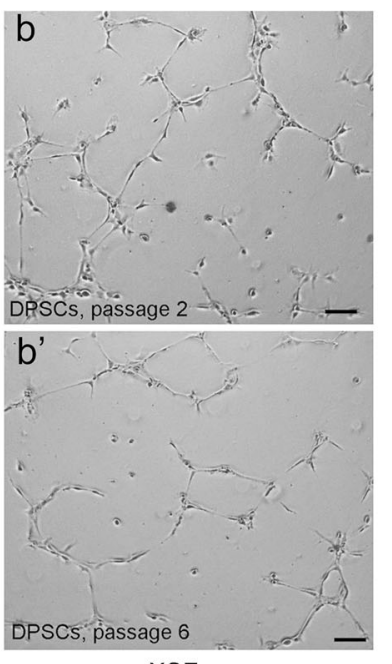

In this study, the aim was to expand and differentiate DPSCs both in XSF and FBS medium, and to further analyze the effect of these various culture conditions on proliferation, phenotype, and differentiation capacity, angiogenic effects of DPSCs, and the expression levels of MSC-associated CD markers.
Fig. 3 In vitro angiogenesis assay. In vitro angiogenesis assay with HUVECs plated on ECMatrix ${ }^{\mathrm{TM}}$ with addition of conditioned media from XSF- or FBS-cultured DPSCs originating from passage 2 or passage 6. Representative images from one donor are shown in $\left(a, b^{\prime}\right)$. Quantification of the angiogenesis assay assessing the number of closed networks (c) and total length of the capillary-like networks (d) from the

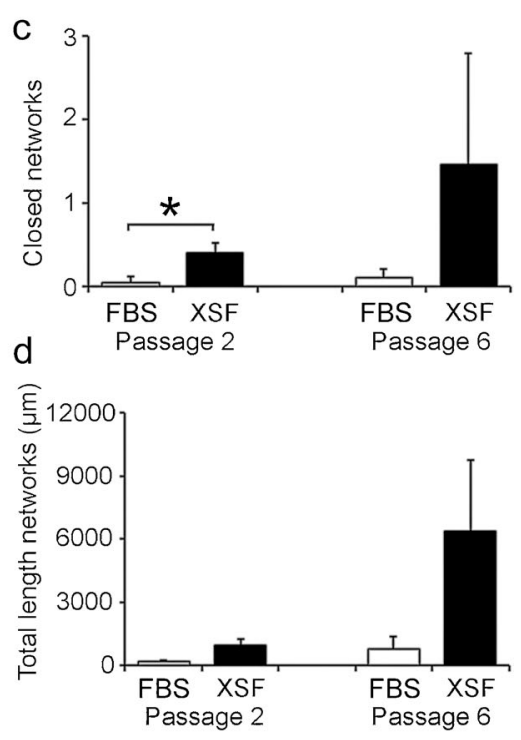

conditioned medium secreted from 2000 DPSCs. The data shows the average calculated from at least 15 random regions from each culture condition/donor. The experiments were repeated three times with DPSCs from three individual donors $(N=3 ; n=3)$. The histograms show mean $\pm \mathrm{SD}$ from three individual donors. * represents $p<0.05$. Scale bar $=100 \mu \mathrm{m}$ 


\section{Cell proliferation and colony-forming unit assays}

The morphological appearance of DPSCs at passage 3 was more elongated and thinner with long protrusions when cultured in XSF compared with FBS (Fig. 1(a, $\left.\mathrm{b}^{\prime}\right)$ ). Moreover, this phenomenon became more apparent by sub-culturing through to passage 6 (Fig. 1(c, d')). Cell proliferation under XSF or FBS culture conditions was examined by counting the cells at each passage up to passage 6. Cumulative population doublings (PDs) showed an initial linear trend for the DPSCs-cultivated in both XSF and FBS medium (Fig. 1(e)). However, a statistically significantly lower number of cumulative PDs in XSF versus FCS medium was detected by passage 6 (Fig. 1(e)).

We then proceeded to compare other properties of the early versus late passage cells. The CFU assay showed that DPSCs at passage 2 and passage 6 had significantly lower numbers of CFUs in XSF versus FBS medium (Fig. 1(f)). However, no significant difference was detected in the number of CFUs between passages in either XFS or FBS medium (Fig. 1(f)). No CFUs could be detected in XSF-expanded cells at passage 6 (Fig. 1(f)).

\section{Angiogenic factor expression}

Angiogenic factors from DPSCs cultured in XSF or FBS were analyzed at gene and protein level. The mRNA expression level of ANGPT1 from XSF cultures was significantly higher in DPSCs at passage 6 versus passage 2, but significantly lower than in FBS medium at passage 6 (Fig. 2a). However, the levels of secreted angiopoietin-1 from DPSCs at passage 6 in XSF culture were below the limit of detection of the ELISA (Fig. $2 \mathrm{~b})$ whereas high levels $\left(11,204 \pm 356 \mathrm{pg} / \mathrm{ml} / 10^{6}\right.$ cells $)$ were secreted from DPSCs cultured in FBS, which was significantly higher than that in FBS culture at passage 2. The mRNA expression level of VEGFA showed no significant differences between the two different cell culture conditions (XSF vs. FBS), or between passages (Fig. 2c). However, secreted VEGFA levels were lower at both passages in cells cultured in FBS versus XSF (Fig. 2d). Additionally, VEGFA levels were lower in FBS at passage 6 versus passage 2 (Fig. $2 \mathrm{~d}$ ).

\section{In vitro angiogenesis assay}

In order to investigate the biological activity of the angiogenic factors, conditioned media from the DPSCs grown in XSF or FBS were applied in an in vitro angiogenesis assay. In this assay, the secreted angiogenic factors in the conditioned medium can be evaluated by their effects on tubulogenesis in HUVEC cultures. Our results revealed that HUVECs showed an elongated morphology and formed capillary-like networks when they were exposed to conditioned media from XSF- or FBS-cultured DPSCs (from early and late passage) (Fig. 3(a, b ')). Quantification of the angiogenesis assay indicated a a

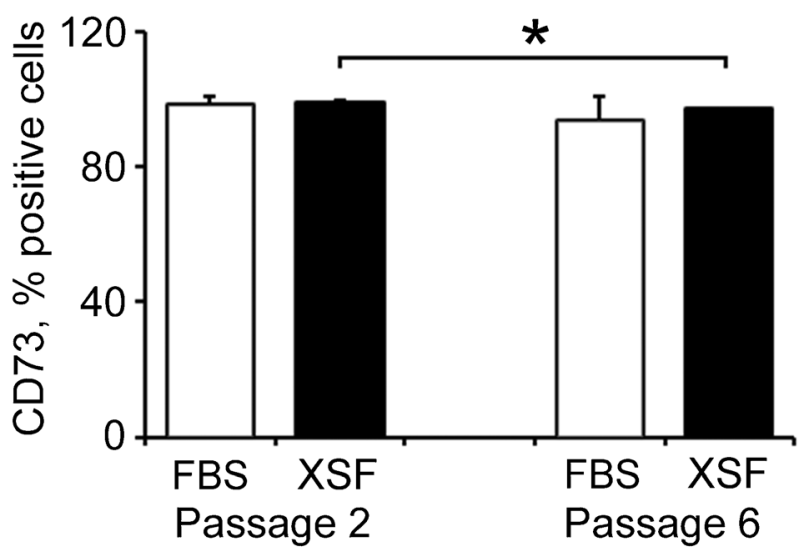

b

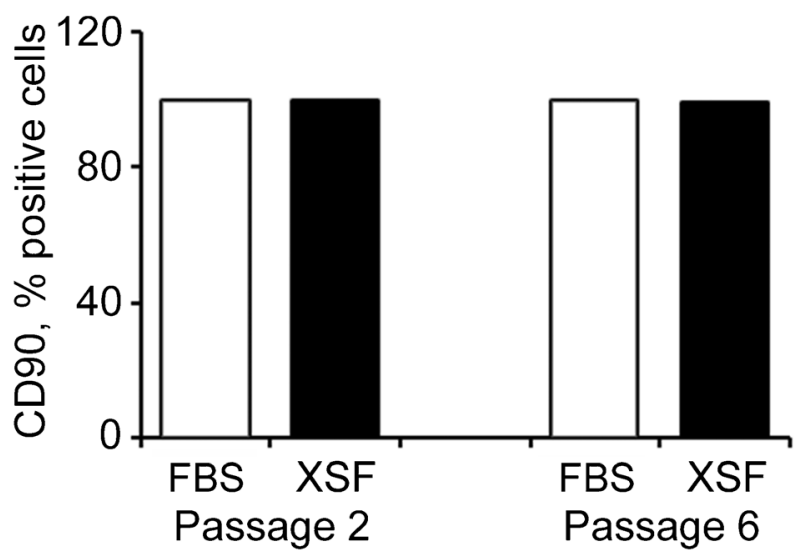

C

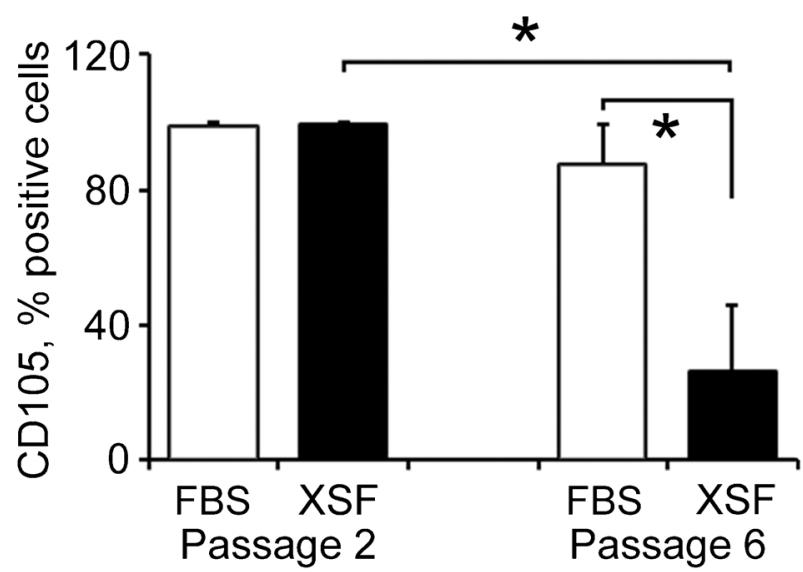

Fig. 4 Flow cytometry analyses of MSC-associated CD surface marker expression. The expression of CD73, CD90, and CD105 were analyzed when the DPSCs at passage 2 and 6 were cultured in XSF or FBS medium. The CD marker expression levels are illustrated in histograms as percentage of cells positive for CD73 (a), CD90 (b), and CD105 (c). The experiments were repeated three times with DPSCs from three individual donors $(N=3 ; n=3)$. The histograms show mean $\pm \mathrm{SD}$ from three different donors. * represents $p<0.05$

significantly higher number of closed networks (a sign of end-point mature networks) in passage 2 DPSCs cultured in 
a

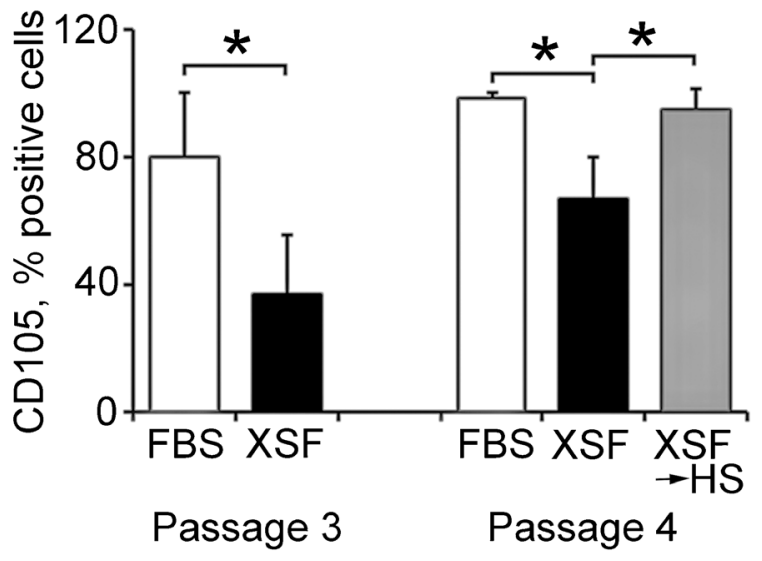

C

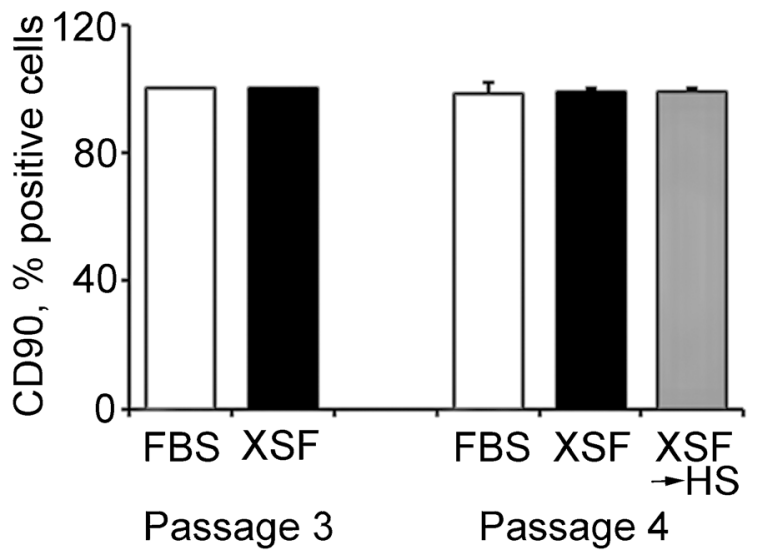

Fig. 5 CD markers expression and morphology of DPSCs when cultured in FCS, XSF, or human serum-supplemented medium (HS). Expression of CD105 (a), CD73 (b), and CD90 (c) in DPSCs-cultured in FBS, XSF, or XSF switched to HS (XSF $\rightarrow$ HS) from passage 3 or passage 4. The experiments were repeated six times with DPSCs from six individual

XSF versus FBS (Fig. 3(c)). The closed networks were even higher in late passage for XSF compared to FBS, but the difference was not statistically significant (Fig. 3(c)). There were no significant differences in the total length of networks between either the two different types of conditioned media or at different passages (Fig. 3(d)).

\section{MSC-associated cluster differentiation surface markers expression}

Flow cytometry analyses showed that the DPSCs expressed CD73, CD90, and CD105 at passage 2 or passage 6 regardless if they were cultured in XSF or FBS medium (Fig. 4). All cultures were negative for the expression of CD11b, CD19, CD34, CD45, and HLA-DR (data not shown). The percentage of cells positive for either CD73 or CD90 was similar in the cultures of XSF or FBS at both passage 2 and passage 6 (Fig. $4 a, b)$. There was a very small but statistically significant decline in the number of CD73-positive cells in XSF medium b
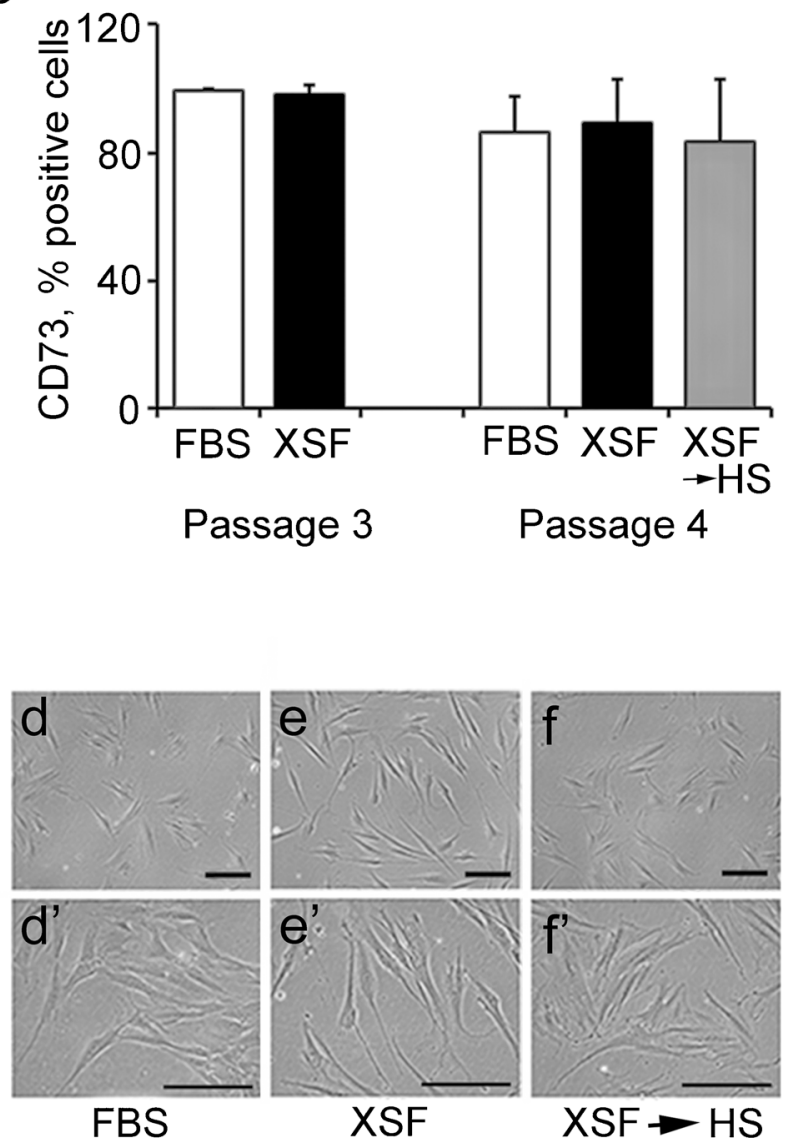

FBS

donors. The histograms show mean \pm SD from six individual donors $(N=6 ; n=6)$. Morphological appearance of DPSCs at passage $4\left(\mathrm{~d}-\mathrm{f}^{\prime}\right)$ when they were cultured in FCS, XSF, or XSF $\rightarrow$ HS medium. * represents $p<0.05$. Scale bar $=100 \mu \mathrm{m}$

at passage 6 versus passage 2 (Fig. 4a). The most noticeable change was the reduction in the number of $\mathrm{CD} 105$-positive cells in XSF medium at passage 6 (Fig. 4c). In contrast, cultures of DPSCs in FBS medium at passage 6 maintained the expression of CD105.

Next, we decided to examine the CD marker expression levels in XSF medium versus FBS medium more in detail at passages earlier than passage 6 in cells from a total of 6 different donors. As early as passage 3 , there was a significant decline in the percentage of CD105-positive cells in XSF medium versus cultures in FBS (Fig. 5(a)). The expression of CD73 and CD90 was not affected (Fig. 5(b, c)). We then trypsinized the passage 3 XSF cells and replated them in medium containing human serum. This significantly restored the percentage of cells expressing CD105 to levels observed in the presence of FBS (Fig. 5a). Furthermore, the exposure of XSF-cultured DPSCs to medium supplemented with human serum altered the elongated cells to a more wide and flat morphology, similar to FCS-cultured cells (Fig. 5(d-f')). 

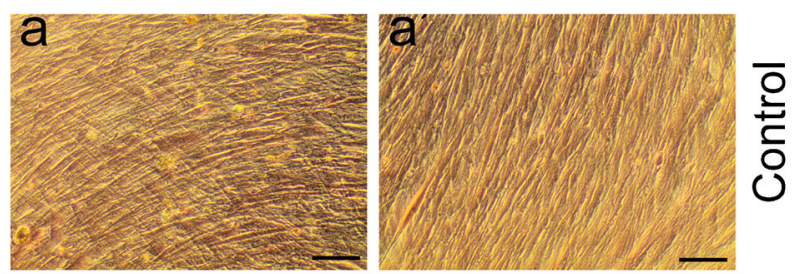

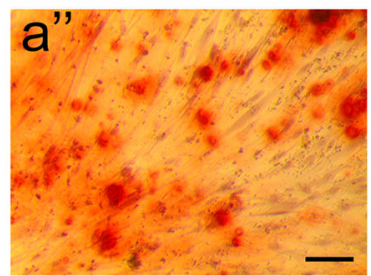

FBS
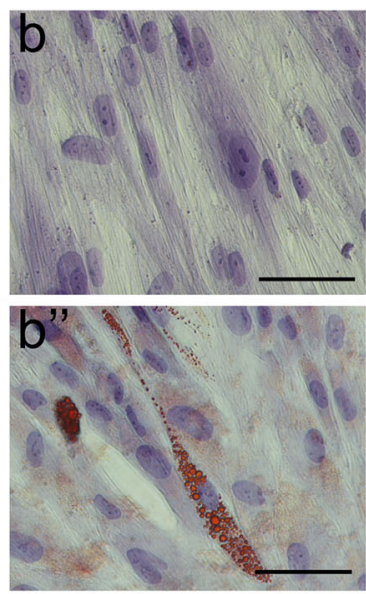

FBS

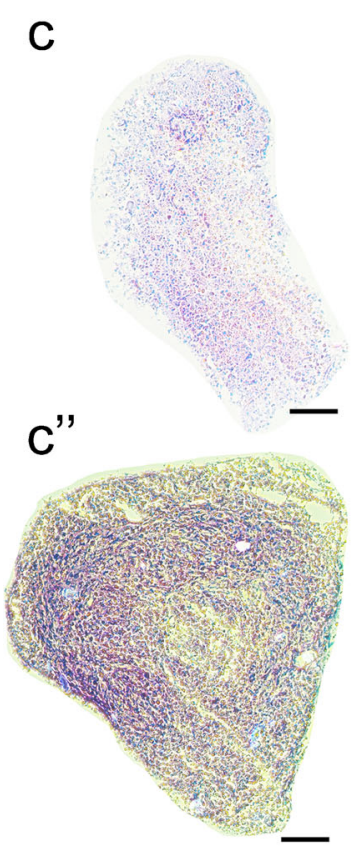

FBS
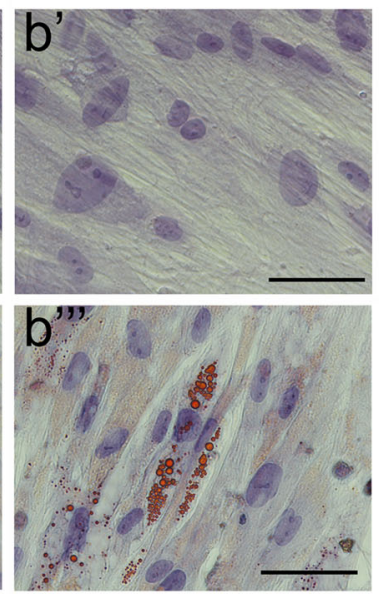

XSF

$c^{\prime}$
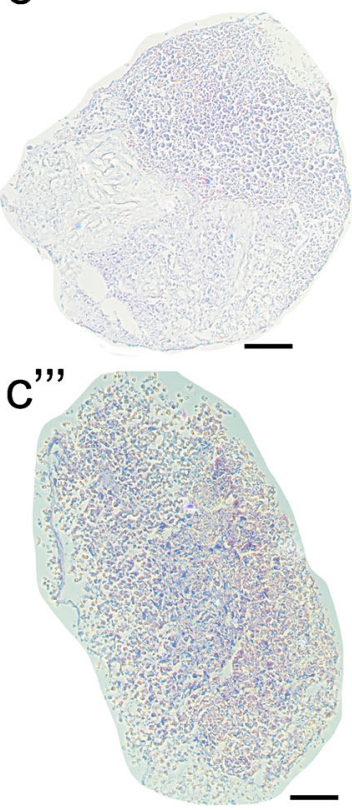

XSF

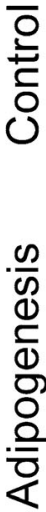

$\frac{\infty}{5}$
$\frac{1}{0}$
$\frac{1}{0}$
0
$\frac{0}{0}$
$\frac{0}{4}$

온

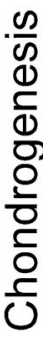

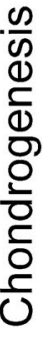

4Fig. 6 Tri-lineage differentiation of DPSCs at passage 5. DPSCs expanded for five passages in either FBS or XSF medium were exposed to control medium or differentiation medium for additional 4 weeks. The control and differentiated cells were analyzed for osteogenic differentiation (Alizarin Red S staining in a, $\mathrm{a}^{\prime \prime \prime}$ ), adipogenic differentiation (Oil Red $\mathrm{O}$ staining in $\mathrm{b}, \mathrm{b}^{\prime \prime \prime}$ ), and chondrogenic differentiation (pellets stained with toluidine blue in $\left.\mathrm{c}, \mathrm{c}^{\prime \prime \prime}\right)$. These experiments were repeated three times with DPSCs from three individual donors $(N=3 ; n=3)$. Representative images from one donor are shown. Scale bar $=100 \mu \mathrm{m}$

\section{Differentiation of dental pulp stem cells}

Since CD105 has been suggested to be an important marker of differentiation potential (Aslan et al. 2006; Levi et al. 2011), we investigated whether the DPSCs differentiation capacity was affected by the culture in XSF medium. After the DPSCs had been expanded in either XSF or FBS medium, DPSCs from passage 5 were differentiated for 4 weeks toward osteoblasts (stained with Alizarin Red S staining, Fig. 6(a", $\left.a^{\prime \prime \prime}\right)$ ), adipocytes (with fatty-droplets stained with Oil Red O staining, Fig. 6(b", b"')), and chondrocytes (proteoglycans stained with toluidine blue, Fig. 6( $\left.\left.\mathrm{c}^{\prime \prime}, \mathrm{c}^{\prime \prime \prime}\right)\right)$. No positive staining was seen in the control cultures of DPSCs (Fig. 6(a, a', b, b', c, c')). There were no obvious differences in the osteogenic and adipogenic differentiation between XSF- and FBS-cultured DPSCs (Fig. 6(a" vs. a"' and b" vs. $\left.b^{\prime \prime \prime}\right)$ ). A slightly stronger proteoglycan staining was visible in the pellet from the DPSCs cultured in FBS medium versus XSF medium, due to the compact pellet that was obtained in FBS-culture (Fig. 6(c" vs. $\left.\mathrm{c}^{\prime \prime \prime}\right)$ ). No positive staining was seen in the control cultures of DPSCs cultured in either XSF or FBS (Fig. 6(c, $\left.\mathrm{c}^{\prime}\right)$ ).

\section{Discussion}

New xeno/serum-free medium formulations produced under cGMP are now commercially available and can be used to avoid animal product contamination of MSC cultures prior to therapeutic cell transplantation. However, little information is available about how the products affect the properties of DPSCs, especially on the expression of CD105 and angiogenic capacity. Moreover, there are conflicting results obtained from the previous studies on DPSCs with serum free medium (Khanna-Jain et al. 2012; Mochizuki and Nakahara 2018). Long-term in vitro expansion of MSCs leads to loss of proliferation and differentiation ability and increased risk of safety concerns. Therefore, the aim of this study was to initially examine the effect of XSF medium in comparison to FBS medium on DPSCs in both early and late passage. We then studied a larger number of donors at clinically relevant passage numbers (2-4) to further investigate the effect on CD105 expression. 
The DPSCs cultured in XSF medium showed more elongated thinner and spindle-shaped fibroblast-like morphology in comparison to the wider and flatter morphology in FBS medium, a result that was consistent with another recent study (Mochizuki and Nakahara 2018). Moreover, we also showed that DPSCs could successfully expand in XSF medium in a similar way as in FBS medium with no significant differences in early passage even though the number of CFUs were lower in XSF. This is consistent with our previous study that showed a different serumfree medium could affect the CFU formation rather than the cell expansion whichever type of MSC were used (Brohlin et al. 2017). The proliferation of DPSCs in serum-free cultures has been shown to be affected by the cell density of initial seeding (Fujii et al. 2018). In another study using DPSCs from primary and permanent teeth, it was shown that the cell viability was lower in some of the tested serum-free medium compared to serum-containing medium, and the proliferation rate of the cells also varied between the tested serum-free medium formulations (Hirata et al. 2010). However, in that study, there was no comparison of the proliferation rate between the control (serum-containing medium) and serum-free medium (Hirata et al. 2010). Various other previous studies have shown that the proliferation rate of DPSCs or other types of MSCs such as BM-MSCs and ASCs was higher when cultured in serum-free medium in comparison to FCS medium (Brohlin et al. 2017; Mark et al. 2013; Mochizuki and Nakahara 2018). This might be due to different components of serum-free medium, different type of cells, or different donors' properties used in the studies.

Angiogenesis, formation of new capillaries from preexisting blood vessels, is of utmost importance in tissue engineering and regenerative medicine. DPSCs have been shown to have angiogenic potential by altering the host environment due to their secreted angiogenic factors, such as VEGFA, angiopoietin-1, platelet-derived growth factor, and fibroblast growth factor (Gandia et al. 2008; Gharaei et al. 2018; Tran-Hung et al. 2008) when cultured in serum-supplemented medium. Our study showed an increased secretion of VEGFA from DPSCs cultured in XSF medium at passages 2 and 6, and this was further confirmed by the evaluation of an in vitro angiogenesis assay, which showed enhanced capillary tube-like formation in XSF-cultured conditioned medium compared with FCS-cultured conditioned medium. These findings are consistent with our previous results using BM-MSCs and ASCs, which showed a significantly increased expression of VEGFA and angiopoietin-1 when they were cultured in another serum-free medium (MesenCult) (Brohlin et al. 2017), and the BM-MSC-conditioned medium enhanced the HUVEC capillary-like formation under serum-free conditions (Brohlin et al. 2017). It has been shown that
VEGF plays an important role in MSC multilineage differentiation and growth (Song et al. 2010). VEGF secreted from MSCs enhances endothelial cell survival and tube formation in HUVECs in vitro (Deveza et al. 2012). Another molecule, angiopoietin-1, an oligomeric-secreted glycoprotein, has been shown to promote vessel stability, and stimulate vessel remodeling and angiogenesis in latter stage of vascular development and in mature vessels (Brindle et al. 2006). Our results showed no difference in the expression level of angiopoietin-1 in DPSCs cultured in XSF versus FBS medium at passage 2, but there was a difference at later passage. It has been shown that serumdeprived cultures of human BM-MSCs secreted higher level of VEGFA and angiopoietins and enhanced microtubule formation in in vitro angiogenesis (Oskowitz et al. 2011). This is similar to our findings with DPSCs which showed better in vitro angiogenesis in XSF medium at passage 2 and 6. This further confirms that DPSCs or SCAPs (apical papilla) have a predominant pro-angiogenic impact on endothelial cell migration and tube formation in vitro and in vivo (Hilken et al. 2014; Bakopoulou et al. 2015).

Our cell characterization showed that the plasticadherent DPSCs expressed MSC-associated CD markers, CD73, CD90, and CD105, but not CD11b, CD19, CD34, CD45, and HLA-DR irrespective of whether they were cultured in XSF or FBS medium, therefore conforming to the minimum criteria of MSCs (Dominici et al. 2006). The most interesting finding was that there was a large decrease in the percentage of DPSCs expressing CD105 in the XSF, even after just three passages. However, switching the XSF-expanded cells to human serum (as the cells would be exposed to upon in vivo transplantation), restored the levels to those found in FBS containing medium. Human serum is probably a golden standard to mimic the in vivo conditions when cells are used for transplantation, even if the cells have been cultured in serum-free or FBS-contained conditions in vitro prior to cell transplantation. Therefore, there is a rational to culture the XFS-cultured DPSCs in human serumsupplemented medium. A few previous studies have indicated that BM-MSCs show a reduced expression of CD105 in serum-free medium (Brohlin et al. 2017; Mark et al. 2013), but this has not been previously reported for DPSCs. So, what might be the consequences of reduced CD105 expression? CD105 (or endoglin) is a transmembrane glycoprotein, which has been identified as an accessory co-receptor of transforming growth factor- $\beta_{1}$ $\left(\right.$ TGF- $\left.\beta_{1}\right)$ and TGF- $\beta_{3}$ (Barbara et al. 1999; Cheifetz et al. 1992; Pierelli et al. 2001) and is generally considered as one of the most important markers of MSCs (Dominici et al. 2006). It has been demonstrated that the expression of CD105 varies depending on MSC sources (Kern et al. 2006; Ponnaiyan and Jegadeesan 2014) and is 
associated with human BM-MSC or ASC differentiation capacity (Cleary et al. 2016; Levi et al. 2011; Ponnaiyan and Jegadeesan 2014). However, conflicting results of the effects of CD105 on the tri-lineage differentiation capacity with BM-MSCs or ASCs has been reported (Cleary et al. 2016; Levi et al. 2011). In our study, the trilineage differentiation of DPSCs showed no clear difference after the cells were cultured in either XSF or FBS medium, even though the CD105 levels were markedly different. This result is consistent with a previous study which used the same XSF medium to isolate and culture DPSCs (Mochizuki and Nakahara 2018). However, in that study, no significantly reduced CD105 expression detected in the DPSCs (Mochizuki and Nakahara 2018). The difference in the donor profiles (for example, age and gender) and the techniques for isolation and culture of the cells with XSF medium in our study and that by Mochizuki et al. (Mochizuki and Nakahara 2018) might cause these conflicting results. Of note, CD105 has also been shown to play an important role in angiogenesis (Nassiri et al. 2011), and we saw in this study a better angiogenesis induced by the medium from late passage cultures containing low levels of CD105-positive DPSCs.

Our study has some limitations. Our donor sample size was small, and our observations are limited to in vitro studies. Future in vivo experiments will be needed to confirm the differentiation ability of the cells after they have been cultured in XSF or FBS medium.

\section{Conclusions}

Taken altogether, this study demonstrated that cGMP-defined xeno-free/serum-free medium could be used to expand DPSCs in vitro, and these cells maintain their ability for trilineage differentiation even though low numbers of the cells expressed the multipotency marker, CD105. The reduction of CD105 expression did not affect the angiogenic capacity of DPSCs. Additionally, the decreased expression of CD105 in XSF medium could be restored when the cells were subsequently cultured in human serum-supplemented medium.

Due to easily obtainable and multipotent capacities, DPSCs have been indicated as a promising source of MSCs in clinical applications (Leyendecker Junior et al. 2018). The needs for DPSC in vitro expansion will increase. Since the serumcontaining culture medium formulations might present safety concerns and suffer from inconsistency in lot-to-lot, new cGMP-defined xeno-free/serum-free media are needed. Our findings demonstrate that the PRIME-XV® MSC expansion XSFM medium (Irvine Scientific) can be considered as an equivalent to medium containing serum for the culture of DPSCs.
Acknowledgments We gratefully thank the Department of Oral and Maxillofacial Surgery (University Hospital of Umeå, Västerbotten County) for assistance in collection of teeth from selected donors and Prof. Mikko Lammi for providing chemicals and suggestions on the chondrogenic differentiation.

Funding information Open access funding provided by Umea University. This project has been funded by grants from the research fund of County Council of Västerbotten (Project Number: 7002408), the Faculty of Medicine, Umeå University (tenure track grant and Insammlingsstiftelsen), and the Swedish Dental Society.

\section{Compliance with ethical standards}

Conflict of interest The authors declare that they have no conflict of interest.

Informed consent Informed consent was obtained from all donors and/ or their legal guardians that are included in the present study.

Ethical approval All procedures performed in studies involving human participants were in accordance with the 1964 Helsinki declaration and were approved by the local ethics committee for research at Umeå University (Dnr 2013-276-31M), and all methods were performed in accordance with the relevant guidelines and regulations of the local ethics committee.

Open Access This article is licensed under a Creative Commons Attribution 4.0 International License, which permits use, sharing, adaptation, distribution and reproduction in any medium or format, as long as you give appropriate credit to the original author(s) and the source, provide a link to the Creative Commons licence, and indicate if changes were made. The images or other third party material in this article are included in the article's Creative Commons licence, unless indicated otherwise in a credit line to the material. If material is not included in the article's Creative Commons licence and your intended use is not permitted by statutory regulation or exceeds the permitted use, you will need to obtain permission directly from the copyright holder. To view a copy of this licence, visit http://creativecommons.org/licenses/by/4.0/.

\section{References}

Aslan H, Zilberman Y, Kandel L, Liebergall M, Oskouian RJ, Gazit D, Gazit Z (2006) Osteogenic differentiation of noncultured immunoisolated bone marrow-derived CD105+ cells. Stem Cells 24:1728-1737

Bakopoulou A, Kristis A, Andreadis D, Papachristou E, Leyhausen G, Koidis P, Geurtsen W, Tsiftsoglou A (2015) Angiogenic potential and secretome of human apical papilla mesenchymal stem cells in various stree microenvironments. Stem Cells Dev 24:2496-2512

Bakopoulou A, Apatzidou D, Aggelidou E, Gousopoulou E, Leyhausen G, Volk J, Kritis A, Koidis P, Geurtsen W (2017) Isolation and prolonged expansion of oral mesenchymal stem cells under clinical-grade, GMP-compliant conditions differentially affects "stemness" properties. Stem cell Research \&Therapy 8:247. https://doi.org/10.1186/s13287-017-0705-0

Barbara NP, Wrana JL, Letarte M (1999) Endoglin is an accessory protein that interacts with the signaling receptor complex of multiple members of the transforming growth factor-beta superfamily. J Biol Chem 274:584-594

Bonnamain V, Thinard R, Sergent-Tanguy S, Huet P, Bienvenu G, Naveilhan P, Farges JC, Alliot-Licht B (2013) Human dental pulp 
stem cells cultured in serum-free supplemented medium. Front Physiol 4:357

Brindle NP, Saharinen P, Alitalo K (2006) Signaling and functions of angiopoietin-1 in vascular protection. Circ Res 98:1014-1023

Brohlin M, Kelk P, Wiberg M, Kingham PJ (2017) Effects of a defined xeno-free medium on the growth and neurotrophic and angiogenic properties of human adult stem cells. Cytotherapy 19:629-639

Cheifetz S, Bellon T, Cales C, Vera S, Bernabeu C, Massague J, Letarte M (1992) Endoglin is a component of the transforming growth factorbeta receptor system in human endothelial cells. J Biol Chem 267: 19027-19030

Cleary MA, Narcisi R, Focke K, van der Linden R, Brama PA, van Osch GJ (2016) Expression of CD105 on expanded mesenchymal stem cells does not predict their chondrogenic potential. Osteoarthr Cartil 24:868-872

Deveza L, Choi J, Imanbayev G, Yang F (2012) Paracrine release from nonviral engineered adipose-derived stem cells promotes endothelial cell survival and migration in vitro. Stem Cells Dev 22:483-491

Dominici M, Le Blanc K, Mueller I, Slaper-Cortenbach I, Marini F, Krause D, Deans R, Keating A, Prockop D, Horwitz E (2006) Minimal criteria for defining multipotent mesenchymal stromal cells. The International Society for Cellular Therapy position statement. Cytotherapy 8:315-317

Fujii S, Fujimoto K, Goto N, Abiko Y, Imaoka A, Shao J, Kitayama K, Kanawa M, Sosiawan A, Suardita K et al (2018) Characterization of human dental pulp cells grown in chemically defined serum-free medium. Biomed Rep 8:350-358

Gandia C, Arminan A, Garcia-Verdugo JM, Lledo E, Ruiz A, Minana MD, Sanchez-Torrijos J, Paya R, Mirabet V, Carbonell-Uberos F et al (2008) Human dental pulp stem cells improve left ventricular function, induce angiogenesis, and reduce infarct size in rats with acute myocardial infarction. Stem Cells 26:638-645

Gharaei MA, Xue Y, Mustafa K, Lie SA, Fristad I (2018) Human dental pulp stromal cell conditioned medium alters endothelial cell behavior. Stem Cell Res Ther 9:69

Gronthos S, Brahim J, Li W, Fisher LW, Cherman N, Boyde A, DenBesten P, Robey PG, Shi S (2002) Stem cell properties of human dental pulp stem cells. J Dent Res 81:531-535

Gronthos S, Mankani M, Brahim J, Robey PG, Shi S (2000) Postnatal human dental pulp stem cells (DPSCs) in vitro and in vivo. Proc Natl Acad Sci U S A 97:13625-13630

Hilken P, Fanton Y, Martens W, Gervois P, Struys T, Politis C, Lambrichtis I, Bronckaers A (2014) Pro-angiogenic impact of dental stem cells in vitro and in vivo. Stem Cell Res 12:778-790

Hirata TM, Ishkitiev N, Yaegaki K, Calenic B, Ishikawa H, Nakahara T, Mitev V, Tanaka T, Haapasalo M (2010) Expression of multiple stem cell markers in dental pulp cells cultured in serum-free media. J Endod 36:1139-1144

Huang GT (2009) Pulp and dentin tissue engineering and regeneration: current progress. Regen Med 4:697-707

Iohara K, Zheng L, Ito M, Tomokiyo A, Matsushita K, Nakashima M (2006) Side population cells isolated from porcine dental pulp tissue with self-renewal and multipotency for dentinogenesis, chondrogenesis, adipogenesis, and neurogenesis. Stem Cells 24:2493-2503

Jo YY, Lee HJ, Kook SY, Choung HW, Park JY, Chung JH, Choung YH, Kim ES, Yang HC, Choung PH (2007) Isolation and characterization of postnatal stem cells from human dental tissues. Tissue Eng 13:767-773

Kaitainen S, Mahonen AJ, Lappalainen R, Kroger H, Lammi MJ, Qu C (2013) TiO2 coating promotes human mesenchymal stem cell proliferation without the loss of their capacity for chondrogenic differentiation. Biofabrication 5:025009

Kern S, Eichler H, Stoeve J, Kluter H, Bieback K (2006) Comparative analysis of mesenchymal stem cells from bone marrow, umbilical cord blood, or adipose tissue. Stem Cells 24:1294-1301
Khanna-Jain R, Vanhatupa S, Vuorinen A, Sandor GKB, Suuronen R, Mannerstrom B, Miettinen S (2012) Growth and differentiation of human dental pulp stem cells maintained in fetal bovine serum, human serum and serum-free/xeno-free culture media. J Stem Cell Res Ther 2

Kim SW, Kim H, Cho HJ, Lee JU, Levit R, Yoon YS (2010) Human peripheral blood-derived CD31+ cells have robust angiogenic and vasculogenic properties and are effective for treating ischemic vascular disease. J Am Coll Cardiol 56:593-607

Kolar MK, Itte VN, Kingham PJ, Novikov LN, Wiberg M, Kelk P (2017) The neurotrophic effects of different human dental mesenchymal stem cells. Sci Rep 7:12605

Laino G, d'Aquino R, Graziano A, Lanza V, Carinci F, Naro F, Pirozzi G, Papaccio G (2005) A new population of human adult dental pulp stem cells: a useful source of living autologous fibrous bone tissue (LAB). J Bone Miner Res 20:1394-1402

Levi B, Wan DC, Glotzbach JP, Hyun J, Januszyk M, Montoro D, Sorkin M, James AW, Nelson ER, Li S et al (2011) CD105 protein depletion enhances human adipose-derived stromal cell osteogenesis through reduction of transforming growth factor beta1 (TGFbeta1) signaling. J Biol Chem 286:39497-39509

Leyendecker Junior A, Gomes Pinheiro CC, Lazzaretti Fernandes T, Franco Bueno D (2018) The use of human dental pulp stem cells for in vivo bone tissue engineering: a systematic review. J Tissue Eng 9:2041731417752766

Mark P, Kleinsorge M, Gaebel R, Lux CA, Toelk A, Pittermann E, David R, Steinhoff G, Ma N (2013) Human mesenchymal stem cells display reduced expression of CD105 after culture in serum-free medium. Stem Cells Int 2013:698076

Mochizuki M, Nakahara T (2018) Establishment of xenogeneic serumfree culture methods for handling human dental pulp stem cells using clinically oriented in-vitro and in-vivo conditions. Stem Cell Res Ther 9:25. https://doi.org/10.1186/s13287-017-0761-5

Mori G, Brunetti G, Oranger A, Carbone C, Ballini A, Lo Muzio L, Colucci S, Mori C, Grassi FR, Grano M (2011) Dental pulp stem cells: osteogenic differentiation and gene expression. Ann N Y Acad Sci $1237: 47-52$

Mortada I, Mortada R (2018) Dental pulp stem cells and osteogenesis: an update. Cytotechnology doi. https://doi.org/10.1007/s10616-0180225-5

Nassiri F, Cusimano MD, Scheithauer BW, Rotondo F, Fazio A, Yousef GM, Syro LV, Kovacs K, Lloyd RV (2011) Endoglin (CD105): a review of its role in angiogenesis and tumor diagnosis, progression and therapy. Anticancer Res 31:2283-2290

Oskowitz A, McFerrin H, Gutschow M, Carter ML, Pochampally R (2011) Serum-deprived human multipotent mesenchymal stromal cells (MSCs) are highly angiogenic. Stem Cell Res 6:215-225

Otaki S, Ueshima S, Shiraishi K, Sugiyama K, Hamada S, Yorimoto M, Matsuo O (2007) Mesenchymal progenitor cells in adult human dental pulp and their ability to form bone when transplanted into immunocompromised mice. Cell Biol Int 31:1191-1197

Otrock ZK, Makarem JA, Shamseddine AI (2007) Vascular endothelial growth factor family of ligands and receptors: review. Blood Cells Mol Dis 38:258-268

Pettersson LF, Kingham PJ, Wiberg M, Kelk P (2017) In vitro osteogenic differentiation of human mesenchymal stem cells from jawbone compared with dental tissue. Tissue Eng Regen Med 14:763-774

Pfaffl MW (2001) A new mathematical model for relative quantification in real-time RT-PCR. Nucleic Acids Res 29:e45

Pierelli L, Bonanno G, Rutella S, Marone M, Scambia G, Leone G (2001) CD105 (endoglin) expression on hematopoietic stem/progenitor cells. Leuk Lymphoma 42:1195-1206

Piva E, Tarle SA, Nör JE, Zou D, Hatfield E, Guinn T, Eunanks EJ, Kaigler D (2017) Dental pulp tissue regeneration using dental pulp stem cells isoalted and expanded in human serum. J Endod 43:568574 
Ponnaiyan D, Jegadeesan V (2014) Comparison of phenotype and differentiation marker gene expression profiles in human dental pulp and bone marrow mesenchymal stem cells. Eur J Dent 8:307-313

Qu C, Lindeberg H, Ylarinne JH, Lammi MJ (2012) Five percent oxygen tension is not beneficial for neocartilage formation in scaffold-free cell cultures. Cell Tissue Res 348:109-117

Qu C, Rilla K, Tammi R, Tammi M, Kroger H, Lammi MJ (2014) Extensive CD44-dependent hyaluronan coats on human bone marrow-derived mesenchymal stem cells produced by hyaluronan synthases HAS1, HAS2 and HAS3. Int J Biochem Cell Biol 48:4554

Qu C, Kaitainen S, Kröger H, Lappalainen R, Lammi MJ (2016) Behaior of human bone marrow-derived mesenchymal stem cells on various titanium-based coatings. Materials. 9:827

Rehman J, Li J, Orschell CM, March KL (2003) Peripheral blood "endothelial progenitor cells" are derived from monocyte/macrophages and secrete angiogenic growth factors. Circulation 107:1164-1169

Studer D, Lischer S, Jochum W, Ehrbar M, Zenobi-Wong M, ManiuraWeber K (2012) Ribosomal protein 113a as a reference gene for human bone marrow-derived mesenchymal stromal cells during expansion, adipo-, chondro-, and osteogenesis. Tissue Eng Part C Methods 18:761-771
Song SY, Chung HM, Sung JH (2010) The pivotal role of VEGF in adipose-derived-stem-cells-mediated regeneration. Expert Opin Biol Ther 10:1529-1537

Tabatabaei FS, Torshabi M (2017) In vitro proliferation and osteogenic differentiation of endometrial stem cells and dental pulp stem cells. Cell Tissue Bank 18:239-247

Tran-Hung L, Laurent P, Camps J, About I (2008) Quantification of angiogenic growth factors released by human dental cells after injury. Arch Oral Biol 53:9-13

Xiao J, Yang D, Li Q, Tian W, Guo W (2018) The establishment of a chemically defined serum-free culture system for human dental pulp stem cells. Stem Cell Res Ther 9:191

Zhang W, Walboomers XF, Shi S, Fan M, Jansen JA (2006) Multilineage differentiation potential of stem cells derived from human dental pulp after cryopreservation. Tissue Eng 12:2813-2823

Ziegelhoeffer T, Fernandez B, Kostin S, Heil M, Voswinckel R, Helisch A, Schaper W (2004) Bone marrow-derived cells do not incorporate into the adult growing vasculature. Circ Res 94:230-238

Publisher's note Springer Nature remains neutral with regard to jurisdictional claims in published maps and institutional affiliations. 